\title{
Effects of CCL5 on the biological behavior of breast cancer and the mechanisms of its interaction with tumor-associated macrophages
}

\author{
GAILI AN ${ }^{1,2^{*}}$, FANG WU $^{3 *}$, SHANGKE HUANG ${ }^{1}$, LU FENG $^{1}, \mathrm{JUN} \mathrm{BAI}^{2}$, SHANZHI GU $^{4}$ and XINHAN ZHAO ${ }^{1}$ \\ ${ }^{1}$ Department of Oncology, The First Affiliated Hospital of Xi'an Jiaotong University, Xi'an, Shaanxi 710061; \\ ${ }^{2}$ Department of Clinical Oncology, Shaanxi Provincial People's Hospital, Xi'an, Shaanxi 710068; \\ ${ }^{3}$ Department of Medical Neonatology, The First Affiliated Hospital of Xi'an Jiaotong University; ${ }^{4}$ Department of College \\ of Forensic Medicine, Xi'an Jiaotong University Health Science Center, Xi'an, Shaanxi 710061, P.R. China
}

Received March 13, 2019; Accepted August 20, 2019

DOI: $10.3892 /$ or.2019.7344

\begin{abstract}
The recurrence and metastasis of breast cancer limit the effectiveness of clinical treatments, making them important issues for clinicians to address. Tumor-associated macrophages (TAMs) contribute to regulating the immune system. C-C motif chemokine ligand 5 (CCL5) is an inflammatory chemokine that promotes chemotaxis on cells involved in the immune/inflammatory response. Breast cancer cells that secrete CCL5 act on THP-1 cells, influencing the invasion and metastasis of tumors. However, knowledge remains limited regarding the mechanism underlying the effects of CCL5 on breast cancer cells and TAMs, as well as the mechanisms promoting the migration and invasion of breast cancer. The present study demonstrated that the positive expression of CCL5 was associated with lymph node status and tumor-node-metastasis stage. Treatment with $\geq 20 \mathrm{ng} / \mathrm{ml}$ CCL5 significantly promoted the migration and invasion of MCF-7 and MDA-MB-231 cells. CCL5-small interfering RNA
\end{abstract}

Correspondence to: Professor Shanzhi Gu, Department of College of Forensic Medicine, Xi'an Jiaotong University Health Science Center, 76 Yanta Western Road, Xi'an, Shaanxi 710061, P.R. China E-mail: gushanzhi@mail.xjtu.edu.cn

Professor Xinhan Zhao, Department of Oncology, The First Affiliated Hospital of Xi'an Jiaotong University, 277 Yanta Western Road, Xi'an, Shaanxi 710061, P.R. China

E-mail: zhaoxinhanprof@163.com

*Contributed equally

Abbreviations: TAM, tumor-associated macrophage; MMP, matrix metalloprotease; ECM, extracellular matrix; FBS, fetal bovine serum; NC, negative control; CCL5, C-C motif chemokine ligand 5; PMA, phorbol-12-myristate-13-acetate; NF- $\mathrm{B}$, nuclear factor- $\mathrm{kB}$; HIF- $1 \alpha$, hypoxia inducible factors- $1 \alpha$

Key words: breast cancer, tumor microenvironment, CCL5, tumor-associated macrophage, epithelial-mesenchymal transition intervention significantly decreased the migration and invasion of the two cell types. In vitro, THP-1 cells were successfully induced to become TAMs, which were then recruited via the chemotactic effects of CCL5. This process was achieved through the co-stimulation of phorbol-12-myristate-13acetate, interleukin-4 (IL-4) and IL-13. The nuclear factor- $\kappa \mathrm{B}$ $(\mathrm{NF}-\kappa \mathrm{B})$ signaling pathway was activated to regulate EMT, as well as the migration and invasion process of MCF-7 cells, when co-cultured with TAMs. We also reported that blocking the expression of CCL5 in vivo may significantly inhibit the growth of human breast cancer xenografts. Therefore, targeting CCL5 may be considered as a novel therapeutic strategy for suppressing the invasion and metastasis of breast cancer.

\section{Introduction}

Breast cancer is the most common cancer among females in China, and is the second leading cause of cancer-associated mortality within this population. Recurrence and metastasis are the most important factors affecting the survival of patients (1). Tumor cells depend on the tumor microenvironment to complete the process of invasion and metastasis. Macrophages are the main component of the tumor microenvironment (1). In particular, M2-type macrophages (also known as TAMs) account for $\sim 30-50 \%$ of inflammatory cells in the tumor stroma, and contribute to the occurrence and development of breast cancer $(2,3)$. Clinical studies have linked the quantity and density of TAM to poor prognosis in most tumors, including malignant melanomas and breast, prostate, ovarian, cervical, and lung cancer (3). Clinically, TAMs mainly originate from monocytes in the peripheral blood, and are recruited by chemokines in the vicinity of the tumor, which influence the microenvironment leading to tumor metastasis $(4,5)$. For example, TAMs secrete various extracellular matrix degradation enzymes [such as tissue proteases, matrix metalloproteinases (MMPs), and serine proteases] that degrade the extracellular matrix and promote tumor metastasis (6).

$\mathrm{C}-\mathrm{C}$ motif chemokine ligand 5 (CCL5) is a chemotactic cytokine or chemokine that is widely secreted from natural killer cells, T cells, fibroblasts, epithelial cells, and 
platelets (7). In parallel, CCL5 contributes to the recruitment and stimulation of these cells; however, CCL5 is also secreted by certain tumor cells, such as malignant melanoma cells (8) and ovarian (9), prostate (10), and breast cancer cells (11). The expression of CCL5 is lower in normal breast epithelium cells, but higher in the primary breast tumor site, local lymph nodes, and metastasis sites (11). Therefore, CCL5 must be expressed during the process of malignant transformation in breast cancer (11). Chemokine levels are also positively correlated with the density of TAM and negatively correlated with the prognosis of patients (11). Thus, blocking chemokine receptors or inhibiting their production could inhibit the recruitment of macrophages by tumor cells.

Nuclear factor (NF)- $\kappa \mathrm{B}$ regulates the expression of many chemokines. Out of these chemokines, CCL5 serves as the target gene of $\mathrm{NF}-\kappa \mathrm{B}$, promoting tumor development (12). $\mathrm{NF}-\kappa \mathrm{B}$ and hypoxia inducible factors- $1 \alpha$ (HIF-1 $\alpha)$ may regulate the function of TAMs, being important for the progression and metastasis of tumors (13). Therefore, the current study aimed to detect the expression of CCL5 and its receptor in breast cancer tissues and different breast cancer cell lines. The effects of CCL5 on the proliferation, apoptosis, migration, and invasion of breast cancer cells was investigated by activating or silencing the expression of CCL5. In addition, the chemotactic effect of CCL5 to TAM was studied. Through these analyses, we explored molecular mechanism of CCL5 in the interaction between breast cancer cells and TAM. Our findings nay serve as a theoretical basis for targeting TAMs during the treatment of breast cancer.

\section{Materials and methods}

Human tissue specimens. A total of 65 patients with complete clinical data who underwent breast cancer surgery in The First Affiliated Hospital of Xi'an Jiaotong University and The First Affiliated Hospital of China Medical University from 2010 to 2012 were evaluated. Samples were excluded if the patients received any preoperatively adjuvant chemotherapy, radiotherapy or hormone therapy. All patients were female, aged 29-73 years old. The tumor-node-metastasis (TNM) stage of the surgical tissue samples was determined according to the American Join Committee on Cancer (6th version, 2002) (14). The survival status of all patients was determined from the clinical medical records and by telephone follow-up.

Cell lines and culture. The human breast cancer cell lines MCF-7, MDA-MB-231, SK-BR-3, and T47D were derived from Shanghai Cell Bank, Chinese Academy of Science (Shanghai, China). All cells were cultured in RPMI-1640 medium that was supplemented with $10 \%(\mathrm{v} / \mathrm{v})$ fetal bovine serum (FBS; Biological Industries) and $1 \%(\mathrm{v} / \mathrm{v})$ penicillin/streptomycin (Gibco; Thermo Fisher Scientific, Inc.) at $37^{\circ} \mathrm{C}$ in a humidified incubator with $5 \% \mathrm{CO}_{2}$.

Cell co-culture. Two $\mathrm{ml}$ cell suspension (density $5 \times 10^{4}$ cells $/ \mathrm{ml}$ ) of MCF-7/small interfering RNA (siRNA)-negative control (siNC) or MCF-7/siCCL5 cells were inoculated into 6-well plates and incubated at $37^{\circ} \mathrm{C}$ for $24 \mathrm{~h}$. Then, $1 \mathrm{ml}$ cell suspension of TAMs (density $1 \times 10^{6} / \mathrm{ml}$ ) induced from THP-1 cells (derived from Kunming Cell Bank, Chinese Academy of
Sciences) were inoculated in the upper chamber of the co-culture chamber. To further verify that the migration and invasion of tumor cells induced by co-culture of MCF-7 with TAM were caused by the activation of NF- $\kappa \mathrm{B}$ signaling, the co-culture was pre-treated with PDTC (cat. no. S1808; Beyotime Institute of Biotechnology), a specific blocking reagent of $\mathrm{NF}-\kappa \mathrm{B}$. The optical density (OD) value, as determined by an MTT assay, indicated the proliferation index of cells in different groups: MCF-7/siNC group, MCF-7/siNC + TAM group, MCF-7/siCCL5 group, and MCF-7/siCCL5 + TAM group.

TAM in vitro model. In this study, human monocyte leukemia cell line (THP-1) was selected to obtain a TAM cell model in vitro. THP-1 cells were seeded at $1 \times 10^{6}$ cells/well into 6-well plates, and phorbol-12-myristate-13-acetate (PMA) was added into the well to make its final concentration of $320 \mathrm{nmol} / \mathrm{l}$ and incubated at $37^{\circ} \mathrm{C}$ for $6 \mathrm{~h}$. Then, $20 \mathrm{ng} / \mathrm{ml} \mathrm{IL-4}$ and IL-13 was added at $37^{\circ} \mathrm{C}$ for $18 \mathrm{~h}$, to obtain M2 macrophages (also known as TAM)s. This group was hence defined as PMA+IL4/IL-13 group. Cells treated with PMA only for $24 \mathrm{~h}$ were defined as the PMA group.

Flow cytometry. Cells of THP-1 group, PMA group and PMA + IL- 4/IL-13 group were trypsinized and centrifuged at $4{ }^{\circ} \mathrm{C}$ at $300 \mathrm{x}$ g for $5 \mathrm{~min}$, then washed with PBS twice and centrifuged at $4^{\circ} \mathrm{C}$ at $300 \mathrm{x}$ g for another $5 \mathrm{~min}$. A total of $1 \times 10^{6}$ cells were suspended with $100 \mu \mathrm{l}$ PBS before $10 \mu \mathrm{l}$ CD204 antibody or $5 \mu \mathrm{l}$ CD206 antibody was added, and incubated in the dark at $37^{\circ} \mathrm{C}$ for $60 \mathrm{~min}$. Finally, cells were suspended in $500 \mu 1 \mathrm{PBS}$ and detected by flow cytometry.

CCL5 RNA interference (RNAi). CCL5 specific siRNA was purchased from Qiagen, Inc. The CCL5 siRNA sequence was: Sense 5'-GAAGAAGUGGGUUCAAGAATT-3' and antisense: 5'-UUCUUGAACCCACUUCUUCTT-3'. The NC sequence was: Sense 5'-UUCUCCGAACGUGUCACGUTT-3' and antisense: 5'-ACGUGACACGUUCGGAGA ATT-3'. Transfection was performed using Lipofectamine ${ }^{\circledR} 2000$ (Invitrogen; Thermo Fisher Scientific, Inc.). Cells $\left(5 \times 10^{4}\right.$ per well) were seeded in twelve-well plates $24 \mathrm{~h}$ prior to transfection and transfected with 80 pM siRNA. The effect of siRNA treatment on secretion and expression of CCL5 was determined by ELISA and quantitative real-time PCR 24 or $48 \mathrm{~h}$ post-transfection.

MTT assay. Cells in the logarithmic growth stage were digested by $0.25 \%$ trypsin and were then resuspended in complete medium. Cell number was counted and adjusted, and $100 \mu \mathrm{l}$ of MDA-MB-231 (5x10 cells $/ \mathrm{ml})$ or MCF-7 $\left(1 \times 10^{5}\right.$ cells $\left./ \mathrm{ml}\right)$ cell suspension was inoculated in 96 -well plates. Then, the old culture medium was discarded and the cells were gently washed with PBS. Then, $100 \mu 15 \%$ FBS (Biological Industries) containing medium was added with different concentrations of exogenous CCL5 (5, 10, 20, 30, 40 and $50 \mathrm{ng} / \mathrm{ml}$, PeproTech, Inc.) to each group. After incubation at $37^{\circ} \mathrm{C}$ for 24 or $48 \mathrm{~h}$, $20 \mu \mathrm{l}$ of MTT reagent $(5 \mathrm{mg} / \mathrm{ml})$ was added to each well. Incubation of the cells was continued at $37^{\circ} \mathrm{C}$ for $4 \mathrm{~h}$. Next, $100 \mu \mathrm{l}$ dimethyl sulfoxide was added to each well after the supernatant was discarded. The wells were oscillated for 
5-10 min to dissolve the crystals fully. The OD value of each well was measured at $492 \mathrm{~nm}$ with a multi-function microplate reader.

RNA extraction and reverse transcription-quantitative polymerase chain reaction ( $R T-q P C R)$. Total RNA was isolated from breast cancer cells or specimens using TRIzol reagent (Thermo Fisher Scientific, Inc.). cDNA was synthesized using a PrimeScript RT reagent kit (Fermentas; Thermo Fisher Scientific, Inc.). RT was performed on the PCR amplification instrument at $37^{\circ} \mathrm{C}$ for $15 \mathrm{~min}, 85^{\circ} \mathrm{C}$ for $5 \mathrm{sec}, 4^{\circ} \mathrm{C}$ maintained to terminal. The synthesized cDNA was stored at $-20^{\circ} \mathrm{C}$. qPCR was carried out according to the manufacturer's instructions for the SYBR ${ }^{\circledR}$ Green PCT kit (Takara Bio, Inc.). The primers used in the present study were: CCL5 sense, 5'-ACACCCTGC TGCTTTGCCTACA-3', antisense, 5'-TCCCGAACCCATTTC TTCTCTG-3', GAPDH sense, 5'-ACCACAGTCCATGCC ATCAC-3', antisense, 5'-TCCACCACCCTGTTGCTGTA-3'; C-C chemokine receptor type 5 (CCR5) sense, 5'-ATCACT TGGGTGGTGGCTGTGTTTG-3', antisense: 5'-CCCTGT GCCTCTTCTTCTCATTTCG-3'; CCR1 sense, 5'-ACCACA GAGTTTGACTATGGGGATG-3', antisense, 5'-AGGGAA GCGTGAACAGGAAGAGCAG-3'; CCR3 sense, 5'-GAG ACTGAAGAGTTGTTTGAAGAGA-3', antisense, 5'-GAT TGATAGGAAGAGAGAAGGATAG-3' Blank controls with no cDNA templates were used to rule out contamination. The thermocycling conditions were as follows: $95^{\circ} \mathrm{C}$ for $30 \mathrm{sec}$, followed by 40 cycles of $95^{\circ} \mathrm{C}$ for $5 \mathrm{sec}, 60^{\circ} \mathrm{C}$ for $30 \mathrm{sec}$, one cycle of $95^{\circ} \mathrm{C}$ for $15 \mathrm{sec}, 60^{\circ} \mathrm{C}$ for $30 \mathrm{sec}$ and $95^{\circ} \mathrm{C}$ for $15 \mathrm{sec}$. The specificity of the PCR product was confirmed by melting curve analysis. At the extension stage of each cycle, the value of the quantification threshold cycle $(\mathrm{Ct})$ value was recorded. GAPDH was used as an internal control. The relative expression level of the target genes was assessed using the $\Delta \Delta \mathrm{Cq}$ method.

Enzyme-linked immunosorbent assay (ELISA). To quantify the secretion of CCL5, cells were cultured in normal medium. The supernatant was collected after 24,48 , and $72 \mathrm{~h}$ incubation. The secretion of CCL5 was quantified using commercial Human RANTES and CCL5 ELISA kits (R\&D Systems, Inc.) following the manufacturer's instructions.

Cell migration and invasion assay. A cell migration assay was carried out using a 24 -well chamber. In total, $5 \times 10^{3}$ cells/well of MDA-MB-231 and 1x10 ${ }^{4}$ cells/well of MCF-7 were suspended in the upper chamber of the well in $200 \mu \mathrm{l}$ RPMI-1640 with no serum. Then, $600 \mu \mathrm{l}$ RPMI-1640 containing 10\% FBS with rhCCL5 (R\&D Systems, Inc.) at different concentrations $(0,10,20 \mathrm{ng} / \mathrm{ml})$ was loaded in the bottom chamber. After incubation at $37^{\circ} \mathrm{C}$ for $18 \mathrm{~h}$ (MDA-MB-231 cells) or $24 \mathrm{~h}$ (MCF-7 cells), the Transwell chambers were fixed in $4 \%$ formaldehyde for $30 \mathrm{~min}$ and stained with $0.01 \%$ crystal violet at room temperature for $20 \mathrm{~min}$. Non-migrating cells were carefully removed from the upper surface of the inside well. Cells that had migrated to the bottom surface of the filter were counted. Five random high-power fields were visualized using an inverted phase-contrast microscope at x200 magnification. The means were obtained for the statistical analysis. Invasion assays were performed in a similar manner to migration assays, except that the cells were placed in the upper chamber with a Matrigel-coated membrane. After incubation at $37^{\circ} \mathrm{C}$ for $36 \mathrm{~h}$ (MDA-MB-231 cells) or $48 \mathrm{~h}$ (MCF-7 cells), fixation and staining were performed.

Western blot analysis. Cells were harvested, and total protein was extracted from the cell lines. Nuclear protein was isolated by using a Nuclear Extraction kit, according to the manufacturer's instructions (Pioneer Biotechnology, Inc.), and protein concentrations were determined using the BCA Protein Assay kit (Pierce; Thermo Fisher Scientific, Inc.). Equal amounts of protein $(150 \mu \mathrm{g})$ were separated by $10 \%$ SDS-PAGE and transferred to a polyvinylidene difluoride (PVDF) membrane (Roche Diagnostics, Inc.). After blocking with $5 \%(\mathrm{w} / \mathrm{v})$ skim milk powder dissolved in TBST at $37^{\circ} \mathrm{C}$ for $1 \mathrm{~h}$, the PVDF membrane was incubated with the primary antibody at $4^{\circ} \mathrm{C}$ overnight. The following primary antibodies $(1: 1,000)$ were used: Anti- $\beta$-actin antibody (sc-47778, Santa Cruz, Biotechnology, Inc.), anti-CCR5 antibody (PA1-41303, Invitrogen; Thermo Fisher Scientific, Inc.), anti-E-cadherin antibody (cat. no. 4065, Cell Signaling Technology, Inc.), anti-N-cadherin antibody (ab76057, Abcam), anti-Vimentin antibody(cat. no. 5741, Cell Signaling Technology, Inc.), anti-Occludin antibody (71-1500, Invitrogen; Thermo Fisher Scientific, Inc.), anti-NF-кB p65 antibody(3034, Cell Signaling Technology, Inc.), and anti-MMP9 antibody (ab73734, Abcam). After extensive washing using TBST, the membrane was incubated with the HRP-conjugated secondary antibodies (1:8,000; goat anti-rabbit, sc-2004; goat anti-mouse, sc-2005) at room temperature for $1 \mathrm{~h}$. Protein bands were visualized with an enhanced chemiluminescence reagent (EMD Millipore), and were analyzed with Quantity One 6.0 software (Bio-Rad Laboratories, Inc). The relative expression of the target protein was expressed with the grayscale value of the target protein $/ \beta$-actin.

Xenograft tumor model. Eight female athymic nude mice (4 weeks old; 18-20 g) were purchased from Shanghai Silaike Laboratory Animal Co., Ltd. Mice were raised in the specific-pathogen free grade experimental animal center of the Medical School of Xi'an Jiaotong University. The experimental process was approved by the ethics committee of Medical and Biological Research of Xi'an Jiaotong University. MCF-7 cells were orthotopically injected into the mammary fat pads of 5 week-old female nude mice. Tumor growth was observed every 2 to 3 days. When the tumors reached $100 \mathrm{~mm}^{3}$ in size, the mice were randomly separated into two groups. The experimental group was intraperitoneally injected with $0.1 \mathrm{ml}$ anti-CCL5 neutralizing antibody $(1 \mu \mathrm{g} / \mathrm{ml}$, ProteinTech Group, Inc.) every 3 days, while the control group was administered the same volume of RPMI-1640 medium. After 30 days, the animals were sacrificed, and the tumors were isolated for immunohistochemical staining. Tumor volume $=\left(\mathrm{a} \mathrm{x} \mathrm{b}^{2}\right) / 2$, where a denotes the longest diameter and $\mathrm{b}$ denotes the shortest diameter of the tumor.

Immunohistochemistry. Paraffin-embedded tissues were retrieved from the Department of Pathology of The First Affiliated Hospital of Xi'an Jiaotong University and The First Affiliated Hospital of China Medical University, and 
$4 \mu \mathrm{m}$ tissue sections were prepared. Paraffin sections were deparaffinized in xylene and were rehydrated through graded alcohols. Antigen retrieval was performed on sections heated in a citrate buffer $(\mathrm{pH}=6.0)$ for $5 \mathrm{~min}$ at $92^{\circ} \mathrm{C}$, and were then cooled naturally at room temperature. The sections were rinsed with TBS after endogenous peroxidase was inactivated with $3 \%$ hydrogen peroxide. After protein blocking with $10 \%$ goat serum (Abcam) at room temperature for $30 \mathrm{~min}$, sections were incubated with primary antibodies (all 1:100) against human CCL5 (cat. no. P230E; Invitrogen; Thermo Fisher Scientific, Inc.), F4/80, CD16, and CD206 (cat. nos. bs-11182R, bs-6028R and bs-21473R, respectively; Beijing Bioss Biotechnology, Ltd.) overnight at $4^{\circ} \mathrm{C}$ and rinsed with TBS. Next, the sections were incubated with secondary antibody for $15 \mathrm{~min}$ at $37^{\circ} \mathrm{C}$, followed by incubation with streptavidin-HRP (Dako; Agilent Technologies, Inc.) for $15 \mathrm{~min}$ at $37^{\circ} \mathrm{C}$, and rinsing with TBS. Peroxidase reactivity was visualized using diaminobenzidine (Dako; Agilent Technologies, Inc.) at room temperature for 3-5 min. Finally, the sections were counterstained with hematoxylin at room temperature for $30 \mathrm{sec}$ and mounted. The number of macrophages in tumor stroma treated with anti-CCL5 neutral antibodies were counted. The positive cell count method was adopted to observe the densest expressed areas of positive cells in tumor stroma under a low power light microscope. Five representative areas were selected from each section, and the number of macrophages was counted and averaged under a 400 -power microscope.

Statistical analysis. All data were expressed as mean \pm standard deviation. Data were analyzed by a Student's t-test or One-way analysis of variance (ANOVA) as appropriate. The Least Significant Difference post-hoc test was used for the post-hoc test following the ANOVA. The relationship between CCL5 protein expression and patient age, lymph node status, and TNM stage was evaluated using a $\chi^{2}$ test. $P<0.05$ was considered to indicate a statistically significant difference. SPSS v 17.0 software (SPSS Inc.) was used. All experiments were repeated independently at least three times.

\section{Results}

Expression of CCL5 in breast cancer tissues, and its relationship with clinical pathology and prognosis. Different expression levels of CCL5 were detected in the cytoplasm of breast cancer cells (Fig. 1). The association between the expression level of CCL5 and the clinicopathological features of breast cancer was analyzed using the immunohistochemical results (Table SI). Stratification analysis showed that there was no significant association between CCL5 expression and patient age, hormone receptor status, or human epidermal growth factor-2 status. However, CCL5 expression was significantly associated with lymph node status and TNM stage $(\mathrm{P}<0.05$; Table SI). Thus, CCL5 may be involved in the invasion and metastasis of breast cancer.

Expression of CCL5 and its receptor in different breast cancer cell lines, and the secretion of CCL5. RT-qPCR was used to determine the levels of CCL5 expression and its receptor in four types of human breast cancer cell lines (MCF-7, MDA-MB-231, SK-BR-3, T-47D). CCL5 expression
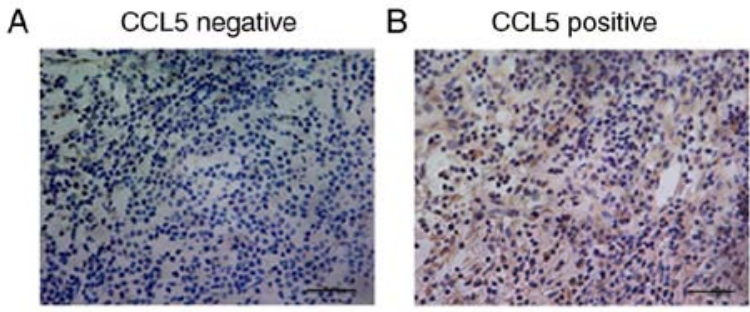

Figure 1. Expression of CCL5 in human breast cancer tissues. (A) CCL5 was negatively expressed; the number of positive cells was $<5 \%$ (magnification $\mathrm{x} 400$ ). (B) CCL5 was positively expressed; brown granules were observed in cytoplasm, and the number of positive cells was $>5 \%$ (magnification $\mathrm{x} 400$ ). CCL5, C-C motif chemokine ligand 5.

was the highest in MCF-7, and lowest in SK-BR-3 cells (Fig. 2A). CCR1 and CCR3 expression was expressed at relatively low levels in all four cell lines, while high CCR5 expression was reported in MCF-7 and MDA-MB-231 cell lines. As a chemokine ligand, CCL5 must combine with the corresponding receptor to function; thus, the relative levels of CCR5 was characterized by Western blot assay. Significantly increased expression of CCR5 was detected in MDA-MB-231 cells compared with MCF-7 cells $(\mathrm{P}<0.05$; Fig. 2B). This result was consistent with the results of mRNA analysis. CCL5 secretion was detected by ELISA, which revealed that MCF-7 cells secreted the most CCL5, while the other three cell lines secreted less (Fig. 2C). CCL5 secretion increased over time (Fig. 2C). In the present study, the association between the constitutive expression of CCL5 in human breast cancer cell lines was investigated. However, the expression levels of CCL5 in breast cancer cells were not consistent with the invasion ability of cell lines. The possible reason is that the expression of CCL5 is affected by certain factors existing around these cells, since the baseline constitutive expression of CCL5 mRNA in these four breast cancer cells was detected without any induction in our study. Therefore, this may not reflect the real ability of different breast cancer cells to express CCL5. We aim to conduct a series of experiments in the future to investigate the migration and invasion of SK-BR-3 cells, which have lower expression levels of CCL5 and CCR5, to serve as a negative control.

CCL5 promotes the proliferation, migration, and invasion of breast cancer cells. An MTT assay was used to detect the effect of different concentrations of CCL5 on cell proliferation. The proliferation of MCF-7 and MDA-MB-231 cells increased significantly following treatment with $\geq 20 \mathrm{ng} / \mathrm{ml}$ CCL5 compared with the blank control ( $\mathrm{P}<0.05$; Fig. 3A). Cell migration and invasion assays showed that the migration and invasion capacity of MCF-7 and MDA-MB-231 cells were enhanced when exogenous CCL5 was added (Fig. 3B and C). When $10 \mathrm{ng} / \mathrm{ml} \mathrm{CCL5}$ was added, both the migration and invasion capacity of MCF-7 cells were significantly enhanced $(\mathrm{P}<0.05)$, while the migration of MDA-MB-231 cells was not; invasion was significantly enhanced $(\mathrm{P}<0.01$; Fig. $3 \mathrm{C})$. When $20 \mathrm{ng} / \mathrm{ml}$ CCL5 was added, the migration and invasion capacity of the two cell lines were significantly increased compared with the control $(\mathrm{P}<0.001$; Fig. $3 \mathrm{~B}$ and $\mathrm{C})$. Thus, CCL5 was proposed to promote the proliferation, migration 

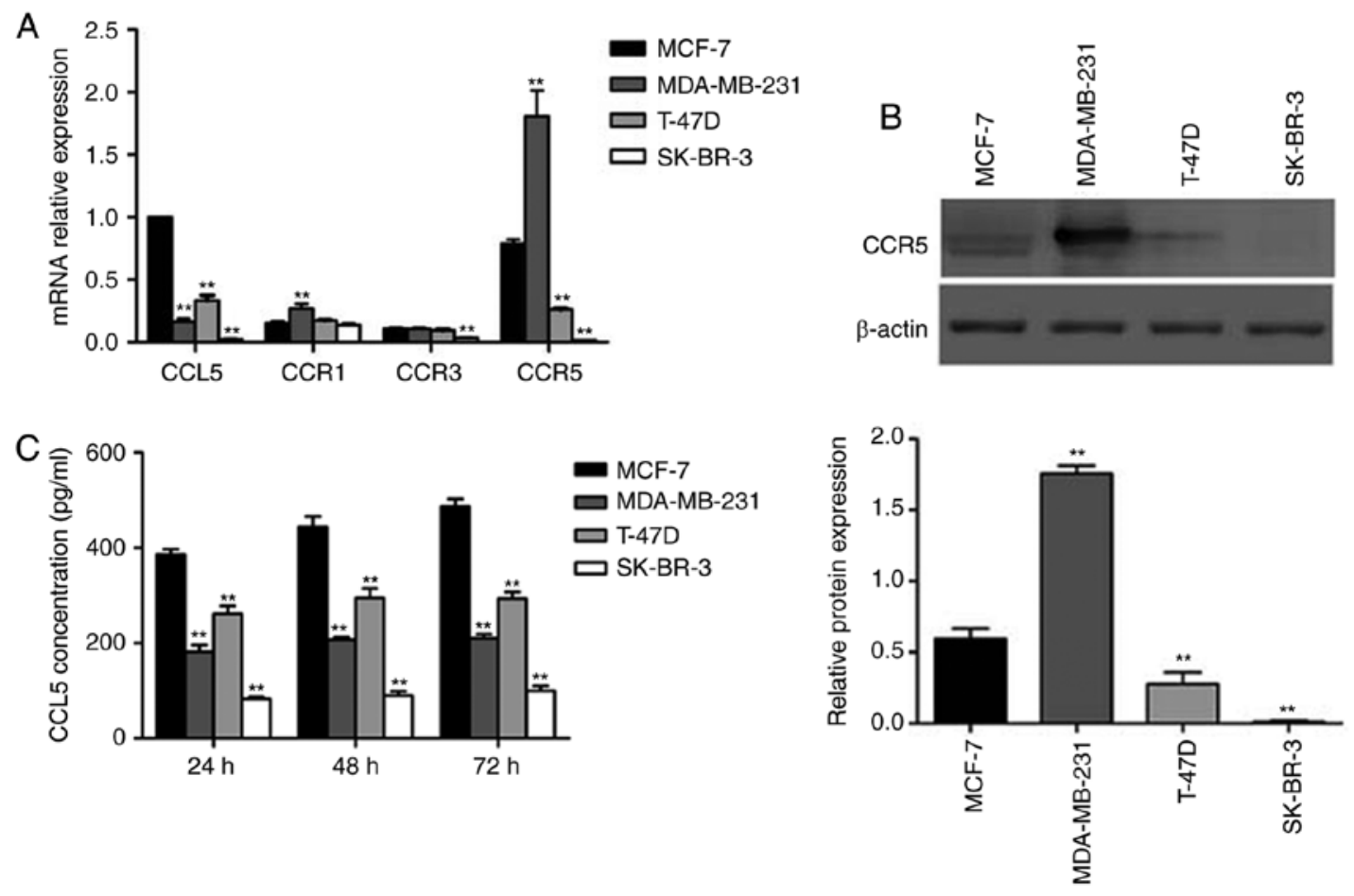

Figure 2. Expression of CCL5 and its receptor in different breast cancer cell lines and the secretion of CCL5. (A) The mRNA expression levels of CCL5, CCR1, CCR3 and CCR5 in different breast cancer cells; MCF-7 cells served as a control, while GAPDH expression was an internal reference. ${ }^{* *} \mathrm{P}<0.01$ vs. control group. (B) The protein expression of CCR5 was detected by western blotting, ${ }^{* *} \mathrm{P}<0.01$ vs. control group. (C) CCL5 secretion in different breast cancer cell lines using ELISA. ${ }^{* *} \mathrm{P}<0.01$ vs. control group. CCL5, C-C motif chemokine ligand 5; CCR1, C-C chemokine receptor type 1; CCR3, C-C chemokine receptor type 3; CCR5, C-C chemokine receptor type 5.

and invasion capabilities of MCF-7 and MDA-MB-231 cells, especially at $20 \mathrm{ng} / \mathrm{ml}$ or greater.

Inhibition of CCL5 affects different biological behaviors in MCF-7 cells. To verify the inhibitory effect of siRNA on CCL5 expression in MCF-7 cells, RT-qPCR and ELISA were used to detect the mRNA expression of CCL5 and CCL5 secretion in the supernatant. Compared with the control and siNC groups, CCL5 mRNA expression and CCL5 secretion in supernatant significantly decreased in the siCCL5 group ( $\mathrm{P}<0.001$; Fig. 4A and B).

An MTT assay was used to detect the proliferation of MCF-7 cells after CCL5 interference. When the CCL5 gene was silenced, there was no statistical difference in the OD values at 24 or $48 \mathrm{~h}$ compared with the $\mathrm{NC}$ group ( $\mathrm{P}>0.05$; Fig. 4C). Flow cytometry showed that, after inhibiting CCL5 expression, the early apoptosis of MCF-7/siCCL5 group cells was not significantly different to that of the MCF-7/siNC group $(6.99 \pm 0.62$ vs. $6.33 \pm 0.58 \%, \mathrm{P}>0.05$; Fig. 4D). The Transwell assay demonstrated that, when inhibiting CCL5 expression, the migration and invasion capacities of MCF-7/siCCL5 cells were significantly reduced compared with the control $(\mathrm{P}<0.001$; Fig. 4E). CCL5 expression in MCF-7 was significantly inhibited by RNA interference; the proliferation and apoptosis of MCF-7 was not markedly affected when CCL5 was downregulated, whereas the migration and invasion capacity of MCF-7 were significantly inhibited.

Generation of TAMs in vitro. Currently, methods for obtaining TAMs include the isolation macrophages from the bone marrow of tumor-bearing mice, or human monocyte THP-1 and mouse monocytes U937 induced by Th2 factor (15). THP-1 is a stable cell line, which can exhibit M2 phenotypic characteristics after induction with PMA and IL-4/IL-13 in vitro, and is recognized as a good model cell to simulate TAMs. In the present study, the human monocyte leukemia cell line THP-1 was selected to obtain TAMs in vitro. CD16 was employed as the molecular marker of M1-type macrophages, and CD206 as the molecular marker of M2-type macrophages. Morphological observations revealed that THP-1 cells grew in suspension with a round shape, while some cells grew in clusters and forming grape-like clusters under normal conditions (Fig. 5A). After adding $320 \mathrm{nmol} / \mathrm{l} \mathrm{PMA}$ for $24 \mathrm{~h}$, the morphology of THP-1 cells changed; some were larger with a long fusiform shape and stretched out pseudopods, presenting macrophage morphology (Fig. 5A).

After $320 \mathrm{nmol} / 1$ PMA was added for $6 \mathrm{~h}$, THP-1 cells adhered to the cell wall. When $20 \mathrm{ng} / \mathrm{ml} \mathrm{IL-4}$ and IL-13 were added for $18 \mathrm{~h}$, the shape of THP-1 cells became irregular, with most extending their pseudopods, namely TAMs (Fig. 5A). After induction, TAMs were cultured for $24 \mathrm{~h}$, with most cells being irregular in shape with multiple pseudopod protrusions (Fig. 5A). Flow cytometry showed that, in the untreated THP-1 cells, the cell surface expression was $0.91 \pm 0.17 \%$ for CD204 and $0.14 \pm 0.05 \%$ for CD206. However, the cell surface of the PMA group was $67.68 \pm 4.79 \%$ for CD204 and $0.77 \pm 0.18 \%$ for CD206. In the PMA + IL-4/IL-13 group, CD204 expression was $88.71 \pm 3.16 \%$, while that of CD206 was $92.18 \pm 3.16 \%$ (Fig. 5B). In comparison, CD204 and CD206 expression on the cell surface of the PMA + IL-4/IL-13 group 

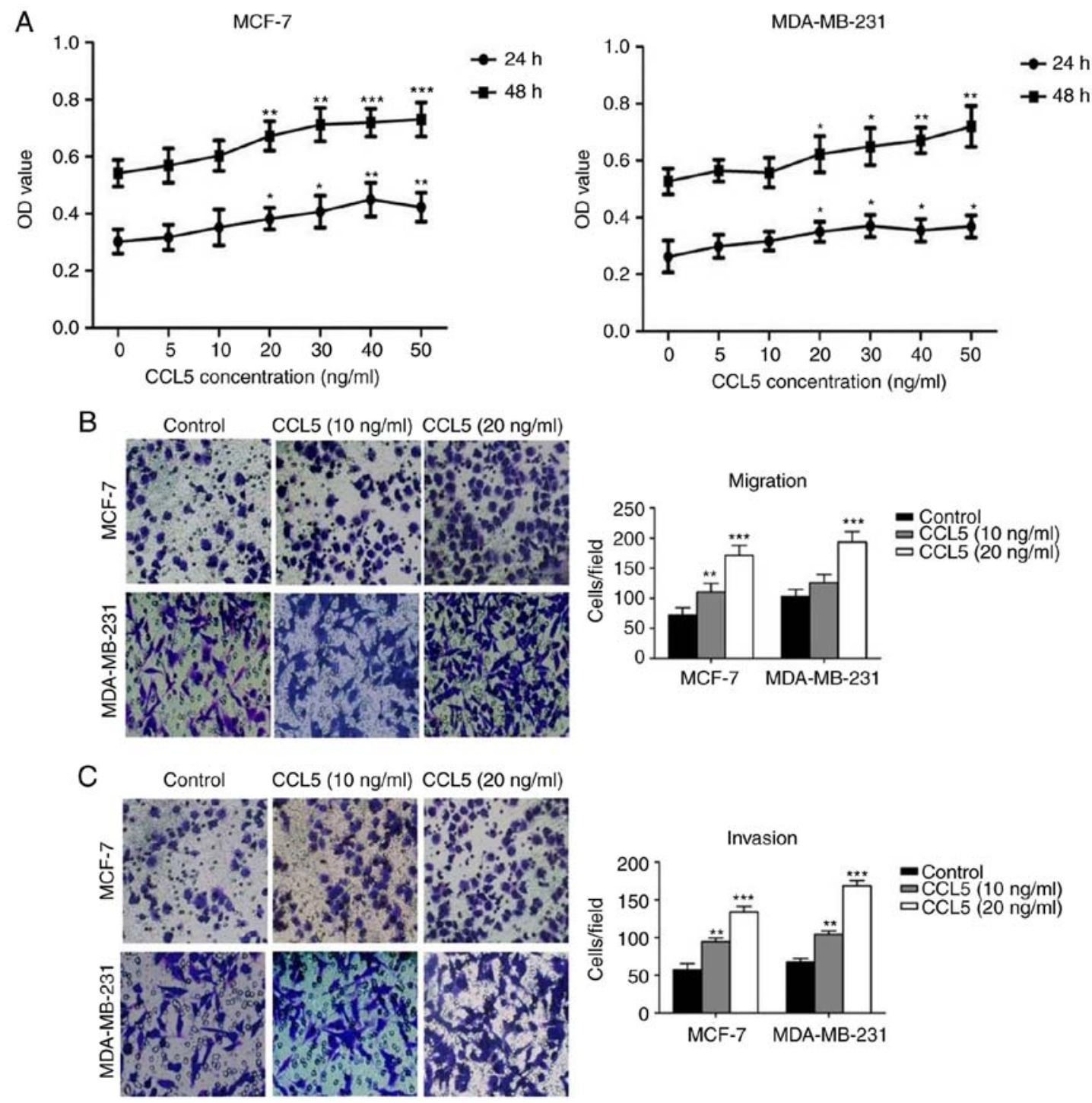

Figure 3. Effects of CCL5 on the proliferation, migration and invasion of breast cancer cells. (A) The effect of CCL5 on the proliferation of breast cancer cells as assessed by an MTT assay. ${ }^{*} \mathrm{P}<0.05,{ }^{* * *} \mathrm{P}<0.01,{ }^{* * * *} \mathrm{P}<0.001$ vs. blank control group $(0 \mathrm{ng} / \mathrm{ml})$. (B and $\left.\mathrm{C}\right)$ The effects of CCL5 on migration and invasion of MCF-7 and MDA-MB-231 cells (magnification x 200). ${ }^{* *} \mathrm{P}<0.05,{ }^{* * *} \mathrm{P}<0.001$ vs. Control group. CCL5, C-C motif chemokine ligand 5; OD, optical density.

was significantly higher than THP-1 ( $\mathrm{P}<0.0001$; Fig. 5B), suggesting the successful induction of TAMs.

A Transwell assay was used to detect CCL5-induced chemotaxis of TAM (Fig. 5C). The chemotaxis potential of MCF-7/siCCL5-conditioned medium to TAMs was significantly weak compared with that of MCF-7/siNC. The complete medium containing CCL5 exerted significant chemotactic ability to TAMs compared with the control $(\mathrm{P}<0.01$; Fig. 5C). Thus, CCL5 was proposed to recruit TAMs in vitro, and that the chemotaxis of TAMs increased with the increasing CCL5 concentration.

MCF-7 cells co-cultured with TAMs promotes cell proliferation, migration and invasion. An MTT assay was used to detect changes to cell proliferation before and after TAMs were co-cultured with MCF-7/siNC or MCF-7/siCCL5. The OD value of MCF-7/siNC co-cultured with TAMs significantly increased compared with MCF-7/siNC $(\mathrm{P}<0.05$; Fig. 6A). However, after interference of endogenous CCL5 in MCF-7 cells, no significant changes in the OD before and after co-culturing with TAMs were reported. The OD was statistically significantly different for MCF-7/siNC + TAMs compared with MCF-7/siCCL5+TAM (P<0.05, Fig. 6A). Therefore, the proliferation capacity of tumor cells had increased after co-culturing, with CCL5 contributing to this process.

The Transwell assay showed that the migration $(\mathrm{P}<0.01)$ and invasion capability $(\mathrm{P}<0.001)$ of $\mathrm{MCF}-7 / \mathrm{siNC}$ cells were significantly enhanced after co-culturing with TAM compared with MCF-7/siNC alone (Fig. 6B). However, endogenous CCL5 interference induced significant differences between MCF-7/siNC + TAM and MCF-7/siCCL5 + TAM ( $\mathrm{P}<0.05$; Fig. 6B). Thus, cell migration and invasion abilities of cells were enhanced by CCL5 after MCF-7 cells were co-cultured with TAMs. The ELISA assay showed that, after co-culturing, the secretion of IL-10, vascular endothelial growth factor (VEGF), tumor necrosis factor (TNF)- $\alpha$ and transforming growth factor (TGF)- $\beta 1$ in the supernatant increased to different extent, and was statistically significant compared with MCF-7/siNC $(\mathrm{P}<0.05$; Fig. 6C). However, when 

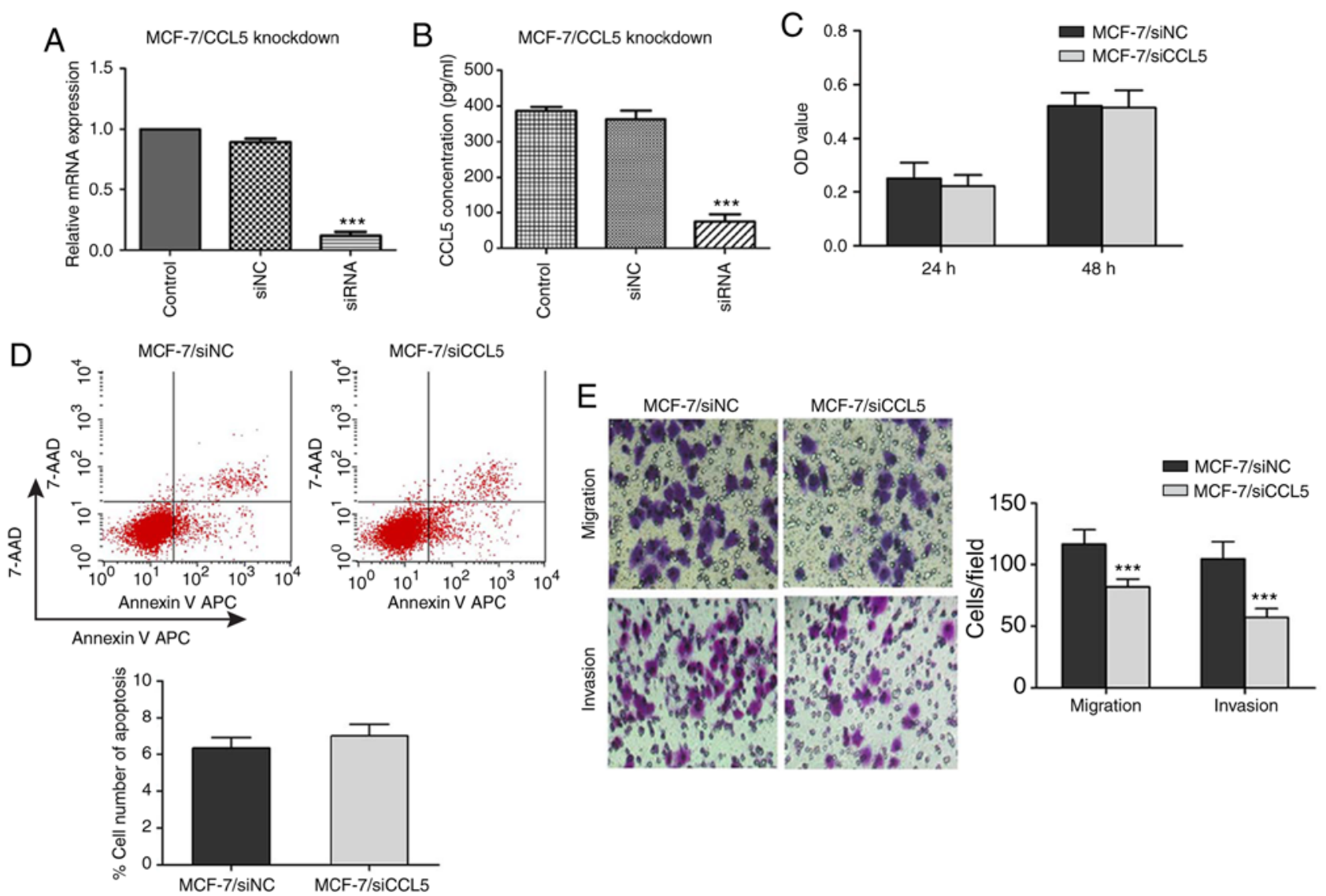

Figure 4. Inhibition of CCL5 affects different biological behaviors of MCF-7 cells. (A and B) After transfection of siRNA, the expression levels of CCL5 mRNA and the secretion of CCL5 protein in the supernatant were detected by reverse transcription-quantitative polymerase chain reaction and ELISA in in each cell group, ${ }^{* * *} \mathrm{P}<0.001$ vs. siNC. (C) Proliferation of MCF-7 cells after inhibiting the expression of CCL5 by MTT. (D) Apoptosis of MCF-7 cells after inhibiting the expression of CCL5, as detected by flow cytometry. (E) Migration and invasion abilities of MCF-7 cells after inhibiting the expression of CCL5 (magnification, $\mathrm{x} 200) .{ }^{* * *} \mathrm{P}<0.001$ vs. MCF-7/siNC group. 7-AAD, 7'aminoactinomycin D; APC, allophycocyanin; CCL5, C-C motif chemokine ligand 5; siNC, negative control; siRNA, small interfering RNA.

MCF-7/siCCL5 cells were co-cultured with TAMs, a significant increase was only observed for the secretion of IL-10 compared with MCF-7/siCCL5 cells ( $\mathrm{P}<0.001$; Fig. 6C). Thus, the secretion of cytokines by TAMs may depends on CCL5.

RT-qPCR showed that the expression of epithelial markers (such as E-cadherin and Occludin) was significantly reduced after co-culturing MCF-7/siNC cells with TAM compared with MCF-7/siNC alone ( $\mathrm{P}<0.01$; Fig. 6D). The mRNA expression levels of mesenchymal markers (such as N-cadherin and Vimentin) were significantly increased compared with MCF-7/siNC alone ( $<<0.001$; Fig. 6D). In comparison, the mRNA expression of EMT markers did not change significantly after MCF-7/siCCL5 cells were co-cultured with TAM (Fig. 6D).

Western blot analysis was conducted to detect the expression of these cell markers (Fig. 6E). After MCF-7/siNC cells were co-cultured with TAMs, the expression of E-cadherin and Occludin was significantly downregulated $(\mathrm{P}<0.05$, Fig. 6E), whereas the expression of $\mathrm{N}$-cadherin and Vimentin was significantly upregulated $(\mathrm{P}<0.05$; Fig. $6 \mathrm{E})$. The expression of these proteins did not significantly change after MCF-7/siCCL5 cells were co-cultured with TAMs, supporting the results of RT-qPCR results (Fig. 6E). Thus, CCL5 may mediate affect the EMT of MCF-7 cells co-cultured with TAMs.
Furthermore, MMP9 protein expression was significantly upregulated after MCF-7/siNC cells were co-cultured with TAMs compared with MCF-7/siNC cells alone $(\mathrm{P}<0.05$; Fig. 7A). However, there were no significant changes in MMP9 protein expression before and after MCF-7/siCCL5 cells were co-cultured with TAMs (Fig. 7A). Thus, MCF-7 cells co-cultured with TAM were proposed to effectively degrade the extracellular matrix in a manner dependent on CCL5.

CCL5 activated the NF- $\kappa B$ signaling pathway by recruiting TAMs to promote tumor migration and invasion. Western blotting revealed that NF- $\kappa \mathrm{B}$ p65 expression was significantly upregulated after MCF-7/siNC cells were co-cultured with TAMs compared with MCF-7/siNC cells alone $(\mathrm{P}<0.05$; Fig. 7B). However, this difference was not statistically significant in MCF-7/siCCL5 cells co-cultured with TAMs or alone. NF- $\kappa \mathrm{B}$ p 65 expression was markedly decreased in MCF-7/siCCL5 cells compared with the MCF-7/siNC group (Fig. 7B). Thus, MCF-7 cells co-cultured with TAM may activate the NF- $\kappa \mathrm{B}$ signaling pathway. On the contrary, the signaling pathway was inhibited after CCL5 interference. After blocking NF- $\kappa \mathrm{B}$ activation with its specific blocker (PDTC), the EMT process was suggested to be reversed and MMP9 expression was downregulated (Fig. 7C). MCF-7 cells co-cultured with TAMs were 
A
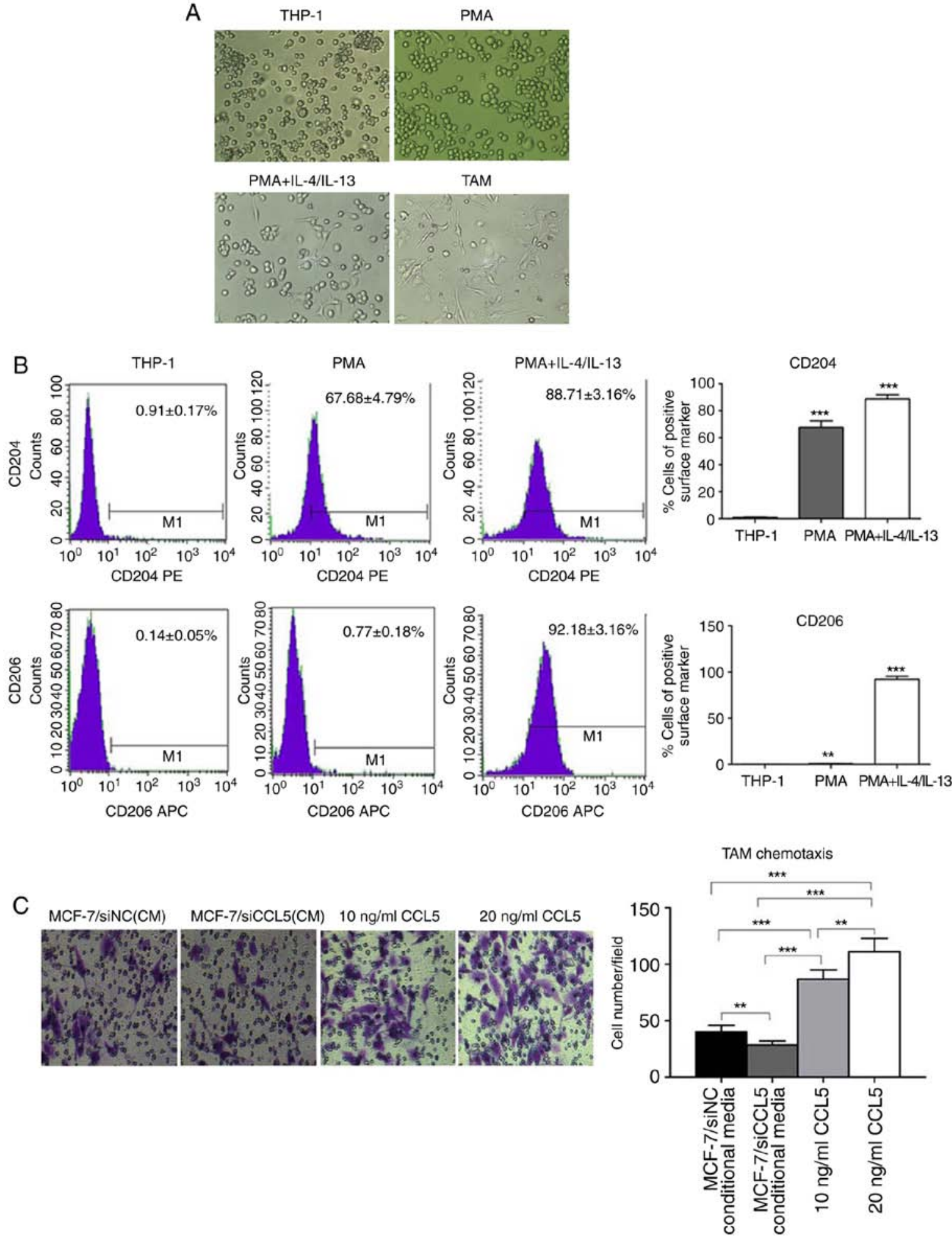

Figure 5. Morphological analysis and surface marker determination of TAMs induced from THP-1 cells in vitro. (A) THP-1 cell morphology (magnification $\mathrm{x} 200$ ) and cell morphology following treatment with PMA for $24 \mathrm{~h}$ (magnification $\mathrm{x} 200$ ). Cell morphology was analyzed following treatment with PMA for $24 \mathrm{~h}$, and IL-4 and IL-13 for $18 \mathrm{~h}$ (magnification x200). TAM cell morphology cultured after $24 \mathrm{~h}$ (x200) was also analyzed. (B) The expression of CD204 and CD206 on the surface of THP-1 cells before and after induction was investigated. ${ }^{* *} \mathrm{P}<0.01,{ }^{* * *} \mathrm{P}<0.0001 \mathrm{vs}$. THP-1. (C) Transwell assay of chemotaxis ability of CCL5 to TAMs (magnification $\mathrm{x} 200$ ), ${ }^{* *} \mathrm{P}<0.01,{ }^{* * * *} \mathrm{P}<0.001$. APC, allophycocyanin; CCL5, C-C motif chemokine ligand 5; IL, interleukin; PMA, phorbol-12-myristate-13-acetate; TAMs, tumor-associated macrophages.

suggested to promote the EMT process of breast cancer cells and increased MMP9 expression by activating the $\mathrm{NF}-\kappa \mathrm{B}$ pathway, which enhanced the migration and invasion of cells. However, silencing the expression of CCL5 did not activate the NF- $\kappa$ B signaling pathway. Thus, CCL5 could contribute to the effects of co-culture by activating the NF- $\kappa \mathrm{B}$ signaling pathway to promote the migration and invasion of tumors. 
A

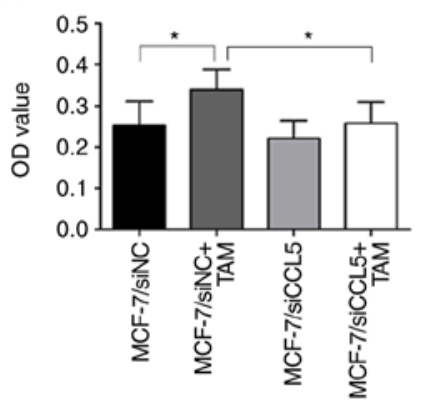

B
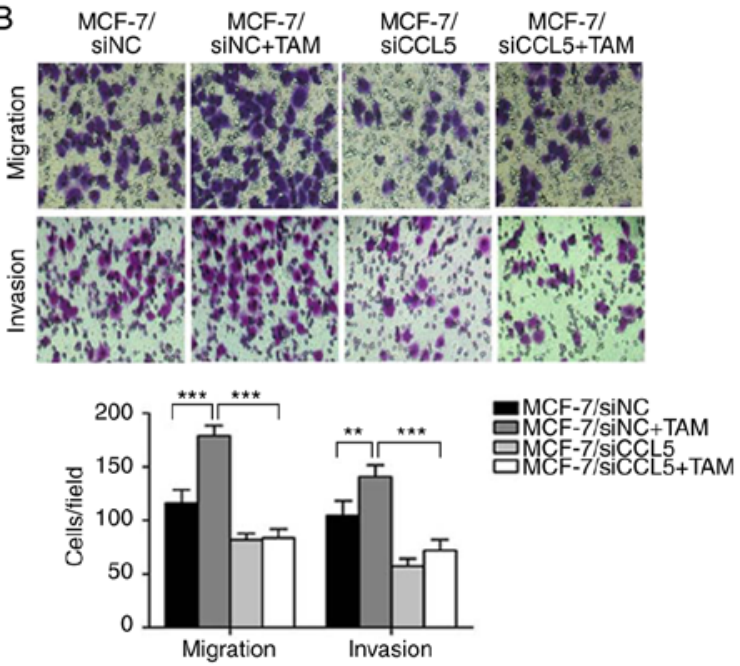

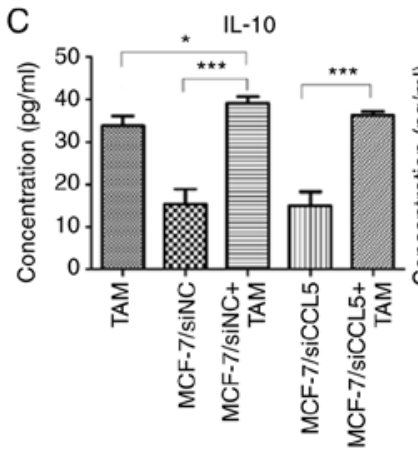

VEGF
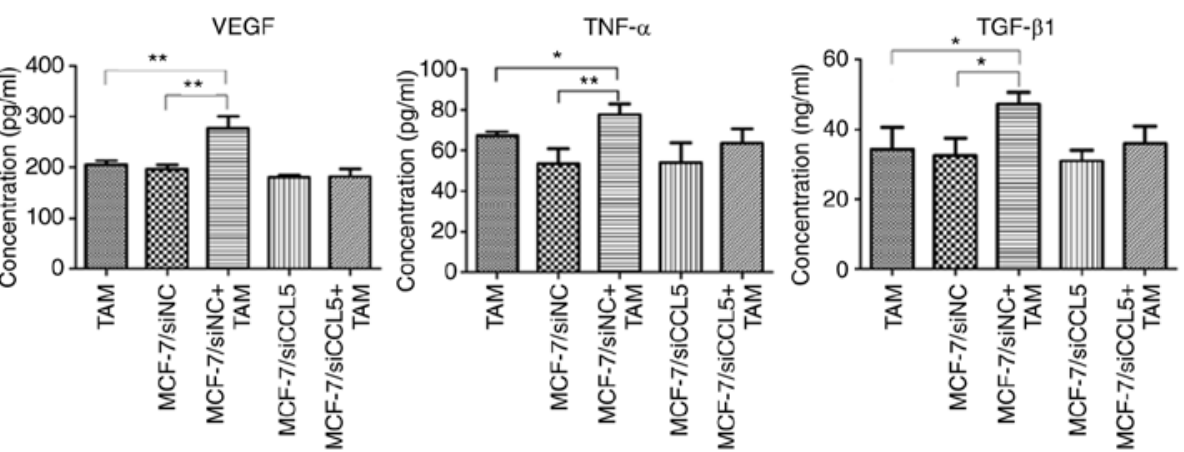

D
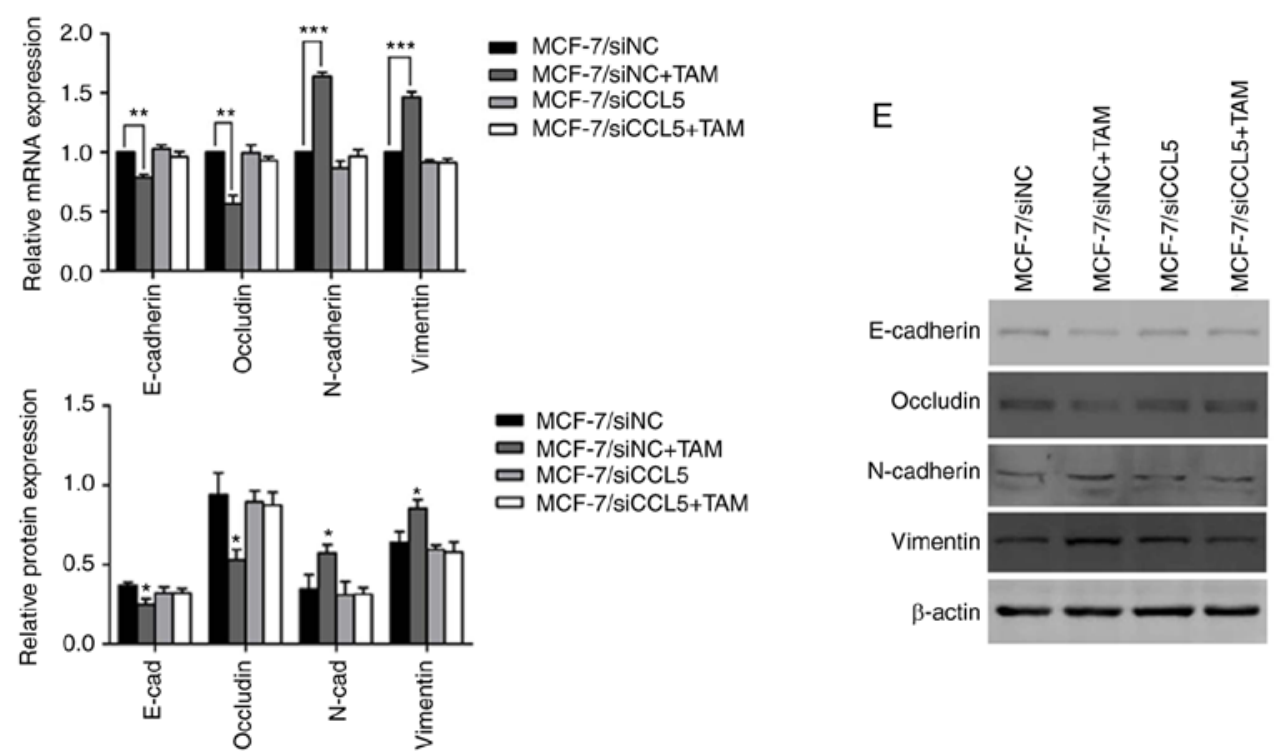

Figure 6. Changes in cell proliferation, migration and invasion before and after MCF-7 cell co-culture with TAMs. (A) The OD value before and after co-culture of MCF-7 cells and TAMs. ${ }^{*}<0.05$. (B) Changes in cell migration and invasion before and after co-culture of MCF-7 cells with TAMs, as determined by a Transwell assay (magnification $\mathrm{x} 200$ ), ${ }^{* * *} \mathrm{P}<0.01,{ }^{* * * *} \mathrm{P}<0.001$. (C) ELISA detection of IL-10, VEGF, TNF- $\alpha$ and TGF- $\beta 1$ in the supernatant before and after co-culture of MCF-7 cells with TAMs. ${ }^{*} \mathrm{P}<0.05,{ }^{* *} \mathrm{P} 0.01,{ }^{* * *} \mathrm{P}<0.001$. (D) The mRNA expression of EMT markers before and after MCF-7 cells were co-cultured with TAMs. ${ }^{* *} \mathrm{P}<0.01,{ }^{* * * *} \mathrm{P}<0.001$. (E) Expression of EMT-related proteins before and after co-culture of MCF-7 with TAMs. " $\mathrm{P}<0.05$ vs. MCF-7/siNC group. E-cad, E-cadherin; EMT, epithelial-mesenchymal transition; OD, optical density; IL, interleukin; N-cad, N-cadherin; siNC, small interfering RNA negative control; siCCL5, small interfering RNA C-C motif chemokine ligand 5; TAMs, associated macrophages; TGF- $\beta 1$, transforming growth factor- $\beta 1$; TNF- $\alpha$, tumor necrosis factor- $\alpha$; VEGF, vascular endothelial growth factor.

CCL5 promotes the growth of human breast cancer xenograft tumor in nude mice. The size of the transplanted tumor significantly differed between the experimental and control groups on day 27 (15 days after CCL5 injection, $\mathrm{P}<0.05$; Fig. 8A and B).
Tumor volume was significantly lower in the experimental group compared with the control group on day 42 (CCL5 injection after 30 days, $\mathrm{P}<0.05$; Fig. $8 \mathrm{~B}$ ). After collecting the tumor tissue, the tumor weight in the experimental group 


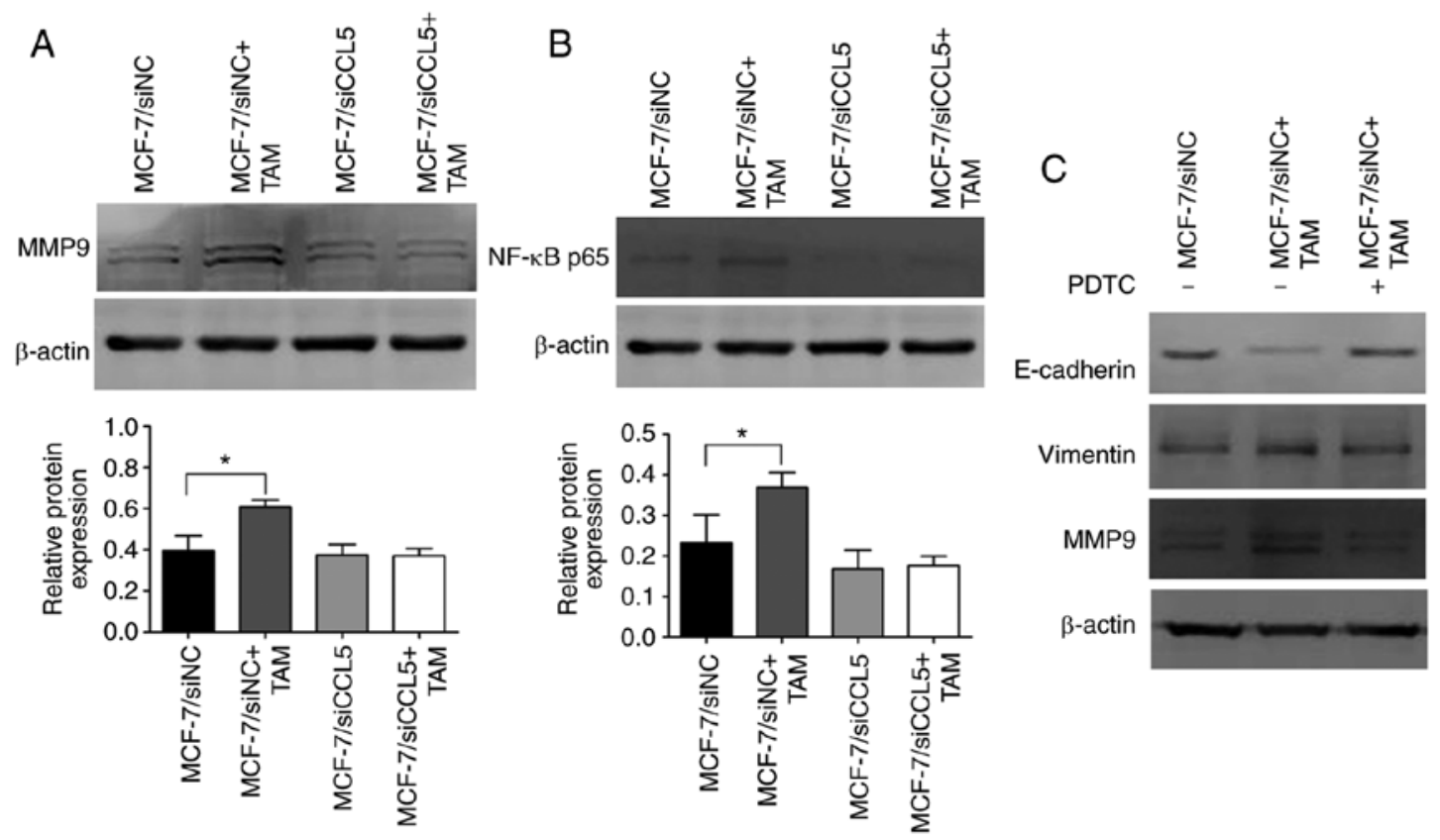

Figure 7. CCL5 activated NF- $\mathrm{B}$ signaling pathway through recruitment of TAM to promote tumor migration and invasion. (A) Expression changes of MMP9 before and after co-culture of MCF-7 cells with TAMs. " $\mathrm{P}<0.05$. (B) Expression of NF- $\kappa B$ before and after co-culture MCF-7 cells with TAMs. "P<0.05.

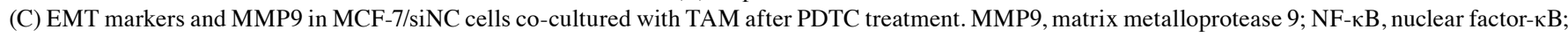
PDTC, pyrrolidinedithiocarbamate; siCCL5, small interfering RNA C-C motif chemokine ligand 5; siNC, small interfering RNA negative control; TAMs, associated macrophages.

\section{A}

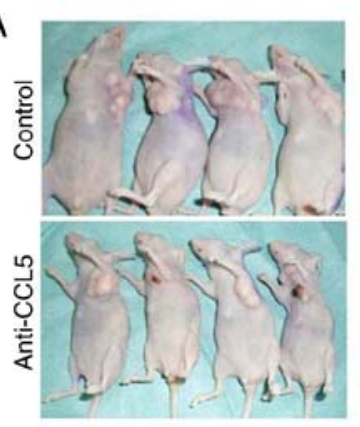

B

D
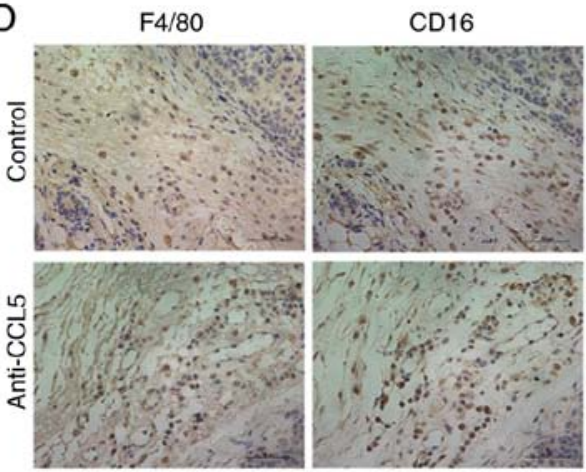

C
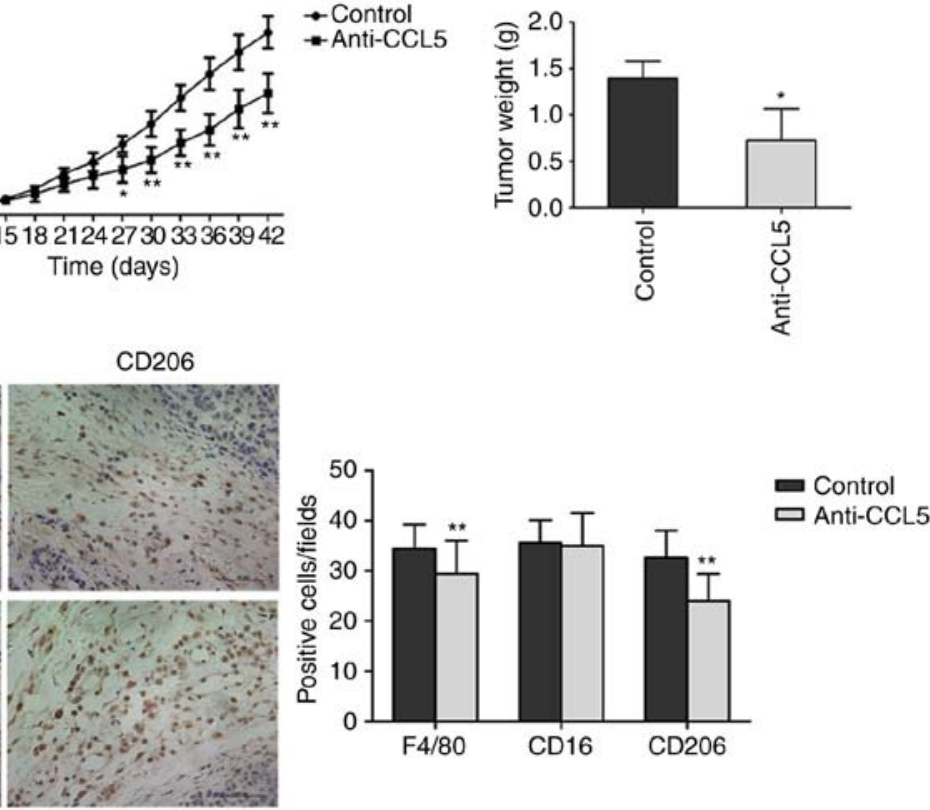

Figure 8. Effects of CCL5 on the growth of human breast cancer xenograft tumor. (A) The xenograft tumor size in nude mice when treated for 30 days. (B) Growth curve of xenograft tumor in nude mice. (C) Nude mice were sacrificed and tumor tissue was obtained on day 30 after administration; the tumor weight was statistically analyzed. ${ }^{*} \mathrm{P}<0.05,{ }^{* *} \mathrm{P}<0.01$ vs. Control group. (D) The infiltration number of different types of macrophages in human breast cancer xenograft tumor in nude mice (magnification, x400). F4/80 represents macrophages; CD16 represents M1-type macrophages; and CD206 represents M2-type macrophages. ${ }^{* *} \mathrm{P}<0.01$ vs. control group. CCL5, C-C motif chemokine ligand 5.

was significantly reduced compared with the control group $(\mathrm{P}<0.05$, Fig. $8 \mathrm{C})$. Thus, CCL5 was suggested to promote the growth of the breast cancer xenograft tumors.
Immunohistochemistry was applied to detect the infiltration of macrophages in tumor tissues after blocking CCL5 secretion (Fig. 8D). Compared with the control group, the 
number of macrophages (Table SII) in tumor stroma treated with anti-CCL5 neutral antibodies was significantly lower compared with the control $(34.93 \pm 4.213$ vs. $30.59 \pm 5.705$, $\mathrm{P}<0.01$; Fig. 8D). The number of M1 type cells did not significantly change ( $36.06 \pm 3.930$ vs. $35.97 \pm 6.058, \mathrm{P}=0.876$; Fig. 8D). The number of M2 type cells was significantly lowered following anti-CCL5 treatment (33.32 \pm 4.857 vs. $24.95 \pm 4.752, \mathrm{P}<0.01$; Fig. $8 \mathrm{D}$ ). Thus, CCL5 in the tumor microenvironment may facilitate TAM recruitment, while blocking CCL5 secretion inhibits TAM recruitment.

\section{Discussion}

Studies have shown that tumor invasion and metastasis are closely related to cells in the tumor microenvironment, with TAMs receiving considerable attention in recent years $(16,17)$. TAMs enhance the migration and invasion abilities of tumor cells by secreting a variety of growth factors and cytokines, promoting the generation of blood vessels and lymphatic vessels, and inducing immune suppression within the microenvironment (16). Angiogenesis, hypoxia and TAM infiltration are associated with the poor prognosis of breast cancer. Correspondingly, decreasing the number of TAMs could reduce tumor progression (18). Lewis et al (18) reported that TAMs secrete VEGF to promote tumor angiogenesis, while hypoxia upregulates the expression of VEGF in TAMs. Nagakawa et al (19) confirmed that TAMs produce various enzymes (such as MMP2 and MMP9) that degrade the extracellular matrix (ECM) and enhance the activity of tumor cells. Soria et al (20) determined that the expression of IL-1, TNF- $\alpha$, CCL5 and CCL2 in breast cancer tissues is significantly higher than that in normal breast tissue. Thus, these four factors may synergistically promote the progression of breast cancer.

The current study established an indirect co-culture system by co-culturing MCF-7 cells with TAMs in a simulated tumor microenvironment in vitro to observe the morphological changes to tumor cells. We reported that MCF-7 cells exhibited a an epithelial-like phenotype, which changed to an interstitial phenotype, with greater intercellular space and reduced adhesion upon induction. An ELISA assay was used to detect the secretion of IL-10, VEGF, TNF- $\alpha$ and TGF- $\beta$ in the supernatant of TAMs only or co-cultured with MCF-7 cells. TAMs and MCF-7 cells secreted all four factors. After co-culture, the secretion of the four factors in supernatant increased. Thus, this co-culture system induces the secretion of a variety of materials that promotes the proliferation, migration and invasion of tumor cells. For instance, Hagemann et al (21) showed that TAMs co-cultured with tumor cells promotes the expression of MMPs, particularly MMP2 and MMP9; this process was conducted in a manner dependent on TNF. In this study, western blotting demonstrated that MMP9 was upregulated after co-culturing MCF-7 cells with TAMs; thus, the co-culture of tumor cells and macrophages increased the secretion of chemical factors and the expression of MMP9.

EMT is an important physiological and pathological process. During the 'lifetime' of tumor cells, the EMT process is continuously activated, causing epithelial cells to lose polarity and gain the properties of mesenchymal cells (22). Consequently, the migration and invasion ability of cancer cells is enhanced, as well as resistance to apoptosis, leading to the secretion of various components that degrade ECM (22). We reported that, after co-culture with TAMs, the migration and invasion abilities of MCF-7 cells were enhanced. Analysis of cell morphology also revealed changes from an epithelial phenotype to a mesenchymal phenotype. RT-qPCR and western blot analyses were used to test the mRNA and protein expression levels of EMT markers in MCF-7 cells. These approaches confirmed that tumor cells underwen EMT changes after co-culture with TAMs. Thus, the migration and invasion of cells was enhanced by EMT.

The high expression of chemokines and their receptors in various tumors activates abnormal signaling pathways, leading to the inactivation of the tumor suppressor gene or the abnormal activation of proto-oncogenes $(23,24)$. As a result, these genes might contribute to the occurrence, metastasis, angiogenesis, EMT, and immune suppression of tumors. The current study demonstrated that the co-culture of MCF-7 cells and TAMs promoted the secretion of various chemical factors, induces the occurrence of EMT, and up-regulates the expression of MMP9; however, the inhibition of CCL5 expression did not cause these changes. We speculated that CCL5 contributes to signal transmission in tumor cells and their microenvironment.

Tumor invasion and metastasis require the occurrence of EMT, as well as tumor angiogenesis, the regulation of various transcriptions and chemical factors, and the secretion of MMPs $(25,26)$. The signaling pathways are involved in ERK/MAPK, PI3K/Akt, Notch, Wnt, Hedgehog, and NF- $\kappa \mathrm{B}$ pathways $(25,26)$. Activated $N F-\kappa B$ promotes the occurrence and development of many tumors, regulating the expression of chemokines, which are mainly homodimers and heterodimers (13). For instance, the heterodimer formed by P65/P50 exists in almost all cells in the body. Heterodimers are present in the cytoplasm in an inactive form in dormant cells. $\mathrm{NF}-\kappa \mathrm{B}$ is activated when cells are stimulated by various factors (13). P65 and P50 are released into the nucleus, causing transcriptional activation or inhibition of corresponding target genes. It has been suggested that transcription factors NF- $\mathrm{BB}$ and HIF-1 $\alpha$ regulate the function of macrophages (13).

CCL5 is a target gene of NF- $\kappa \mathrm{B}$. Huang et al (27) showed that CCL5 activates $\alpha v \beta 3$ integrin through the PI3K/Akt pathway to promote cell migration. In turn, $\alpha v \beta 3$ integrin activates the IKK $\alpha / \beta$ and NF- $\mathrm{BB}$ pathways (27). The activation of $N F-\kappa B$ also promotes the secretion of MMP9. Grivennikov et al (28) had reported that TNF- $\alpha$ secreted by cells causes the secretion of chemical factors, while TAMs are activated by $\mathrm{NF}-\kappa \mathrm{B}$, which activates the pre-feedback loop. The activation of $\mathrm{NF}-\kappa \mathrm{B}$ also increases the production of MMPs, further promoting the degradation of ECM and the release of growth factors (29).

Applying NF- $\kappa \mathrm{B}$ inhibitors or anti-inflammatory drugs, like aspirin, reduces the concentration of NF- $\kappa \mathrm{B}$ downstream protein IL-8 and slows down the progression of colon cancer and breast cancer (30). In the preset study, western blotting was performed to detect the protein expression of NF- $\mathrm{NB}$ p65 before and after MCF-7 cells were co-cultured with TAMs. We found that NF- $\mathrm{NB}$ p65 expression was upregulated after co-culture; thus, it activates the NF- $\kappa \mathrm{B}$ signaling pathway. When blocking $N F-\kappa B$ activation using the inhibitor PDTC, the EMT process was reversed, and the expression of MMP9 
was downregulated. Thus, MCF-7 cells co-cultured with TAMs activate the NF- $\kappa B$ signaling pathway. Finally, through EMT occurrence and MMP9 upregulation, NF- $\mathrm{B}$ pathway activation promotes the migration and invasion of tumor cells. However, CCL5 intervention prevented the co-culture of MCF-7 cells and TAMs showing these changes. Also, the migration and invasion ability of the cells did not significantly change. Thus, CCL5 plays an important role in the interaction between tumor cells and TAM.

The current study revealed that CCL5 promotes tumor migration and invasion. For instance, breast cancer cells and different cells in the tumor microenvironment (such as MSCs) secrete CCL5. The activation of CCL5 recruits TAM into the tumor microenvironment. TAMs interact with tumor cells to secrete a variety of factors (such as VEGF and TNF- $\beta$ ) and promotes the release of MMPs, which activate the NF- $\mathrm{KB}$ signaling pathway to induce EMT occurrence (15). All of these factors promote the proliferation of tumor cells and angiogenesis, as well as the degradation of ECM; consequently, the invasion and metastasis of the tumor are promoted. However, the invasion and metastasis of the tumor are complex processes involving in the interaction of various factors and multiple signaling pathways. In conclusion, it is important to determine whether chemokines, other than CCL5, activate this pathway, and whether other signaling pathways are involved.

\section{Acknowledgements}

We sincerely thank Professor Wei Duan (Deakin University, Australia) for insightful discussions.

\section{Funding}

This study was supported by grants from Basic Research Project of Natural Science in Shaanxi Province: Multi-mode nano-targeted probe for molecular imaging of HER-2 positive breast cancer (grant no. 2017JM8106).

\section{Availability of data and materials}

The datasets supporting the conclusions of this article are included within this article and its additional images. Raw data are available from the corresponding author on reasonable request.

\section{Authors' contributions}

XZ designed the study. GA, FW, SH, JB, LF and SG performed the experiments and analyzed the data. GA and FW wrote the manuscript. XZ and SG helped to revise the manuscript. All authors read and approved the final manuscript and agree to be accountable for all aspects of the research in ensuring that the accuracy or integrity of any part of the work are appropriately investigated and resolved.

\section{Ethics approval and consent to participate}

Ethics approval for the use of human samples was obtained from the Ethical Committee of The First Affiliated Hospital of Xi'an Jiaotong University (approval no. XJTU1AF2018LS
K-247). Written informed consent was obtained from patients. The animal studies were approved by the ethics committee of Medical and Biological Research of Xi'an Jiaotong University.

\section{Patient consent for publication}

Not applicable.

\section{Competing interests}

The authors declare that they have no competing interests.

\section{References}

1. Jemal A, Center MM, DeSantis C and Ward EM: Global patterns of cancer incidence and mortality rates and trends. Cancer Epidemiol Biomarkers Prev 19: 1893-1907, 2010.

2. Mantovani A, Allavena P, Sica A and Balkwill F: Cancer-related inflammation. Nature 454: 436-444, 2008.

3. Sica A, Allavena P and Mantovani A: Cancer related inflammation: The macrophage connection. Cancer Lett 267: 204-215, 2008.

4. Lin EY, Nguyen AV, Russell RG and Pollard JW: Colony-stimulating factor 1 promotes progression of mammary tumors to malignancy. J Exp Med 193: 727-740, 2001.

5. Lin EY and Pollard JW: Macrophages: Modulators of breast cancer progression. Novartis Found Symp 256: 158-168, 2004.

6. Yang J, Liao D, Chen C, Liu Y, Chuang TH, Xiang R, Markowitz D, Reisfeld RA and Luo Y: Tumor-associated macrophages regulate murine breast cancer stem cells through a novel paracrine EGFR/Stat3/Sox-2 signaling pathway. Stem Cells 31: 248-258, 2013.

7. Donlon TA, Krensky AM, Wallace MR, Collins FS, Lovett M and Clayberger C: Localization of a human T-cell-specific gene, RANTES (D17S136E), to chromosome 17q11.2-q12. Genomics 6: 548-553, 1990.

8. Mrowietz U, Schwenk U, Maune S, Bartels J, Küpper M, Fichtner I, Schröder JM and Schadendorf D: The chemokine RANTES is secreted by human melanoma cells and is associated with enhanced tumour formation in nude mice. $\mathrm{Br} \mathrm{J}$ Cancer 79: 1025-1031, 1999

9. Wertel I, Tarkowski R, Bednarek W and Kotarski J: Relationship between RANTES and dendritic cells in ovarian cancer patients. Front Biosci (Elite Ed) 3: 227-232, 2011.

10. Vaday GG, Peehl DM, Kadam PA and Lawrence DM: Expression of CCL5 (RANTES) and CCR5 in prostate cancer. Prostate 66: 124-134, 2006.

11. Soria $G$ and Ben-Baruch A: The inflammatory chemokines CCL2 and CCL5 in breast cancer. Cancer Lett 267: 271-285, 2008.

12. Milliken D, Scotton C, Raju S, Balkwill F and Wilson J: Analysis of chemokines and chemokine receptor expression in ovarian cancer ascites. Clin Cancer Res 8: 1108-1114, 2002.

13. Tang X: Tumor-associated macrophages as potential diagnostic and prognostic biomarkers in breast cancer. Cancer Lett 332: 3-10, 2013.

14. Greene FL, Page DL, Fleming ID, et al: AJCC cancer staging manual. 6th edition. Springer-Verlag, New York, NY, 2002.

15. Tjiu JW, Chen JS, Shun CT, Lin SJ, Liao YH, Chu CY, Tsai TF, Chiu HC, Dai YS, Inoue H, et al: Tumor-associated macrophage-induced invasion and angiogenesis of human basal cell carcinoma cells by cyclooxygenase-2 induction. J Invest Dermatol 129: 1016-1025, 2009.

16. Siveen KS and Kuttan G: Role of macrophages in tumour progression. Immunol Lett 123: 97-102, 2009.

17. Wu H, Xu JB, He YL, Peng JJ, Zhang XH, Chen CQ, Li W and Cai SR: Tumor-associated macrophages promote angiogenesis and lymphangiogenesis of gastric cancer. J Surg Oncol 106: 462-468, 2012.

18. Lewis JS, Landers RJ, Underwood JC, Harris AL and Lewis CE: Expression of vascular endothelial growth factor by macrophages is up-regulated in poorly vascularized areas of breast carcinomas. J Pathol 192: 150-158, 2000.

19. Nagakawa Y, Aoki T, Kasuya K, Tsuchida A and Koyanagi Y: Histologic features of venous invasion, expression of vascular endothelial growth factor and matrix metalloproteinase-2 and matrix metalloproteinase-9, and the relation with liver metastasis in pancreatic cancer. Pancreas 24: 169-178, 2002. 
20. Soria G, Ofri-Shahak M, Haas I, Yaal-Hahoshen N, Leider-Trejo L, Leibovich-Rivkin T, Weitzenfeld P, Meshel T, Shabtai E, Gutman M and Ben-Baruch A: Inflammatory mediators in breast cancer: Coordinated expression of TNF $\alpha$ \& IL-1 with CCL2 \& CCL5 and effects on epithelial-to-mesenchymal transition. BMC Cancer 11: 130, 2011.

21. Hagemann T, Robinson SC, Schulz M, Trümper L, Balkwill FR and Binder C: Enhanced invasiveness of breast cancer cell lines upon co-cultivation with macrophages is due to TNF-alpha dependent up-regulation of matrix metalloproteases. Carcinogenesis 25: 1543-1549, 2004.

22. Lim J and Thiery JP: Epithelial-mesenchymal transitions: Insights from development. Development 139: 3471-3486, 2012.

23. Aldinucci D and Colombatti A: The inflammatory chemokine CCL5 and cancer progression. Mediators Inflamm 2014: 292376, 2014.

24. Cambien B, Richard-Fiardo P, Karimdjee BF, Martini V, Ferrua B, Pitard B, Schmid-Antomarchi H and Schmid-Alliana A: CCL5 neutralization restricts cancer growth and potentiates the targeting of PDGFR $\beta$ in colorectal carcinoma. PLoS One 6: e28842, 2011.

25. Huber MA, Kraut N and Beug H: Molecular requirements for epithelial-mesenchymal transition during tumor progression. Curr Opin Cell Biol 17: 548-558, 2005.
26. Huber MA, Azoitei N, Baumann B, Grünert S, Sommer A, Pehamberger H, Kraut N, Beug H and Wirth T: NF-kappaB is essential for epithelial-mesenchymal transition and metastasis in a model of breast cancer progression. J Clin Invest 114: 569-581, 2004.

27. Huang CY, Fong YC, Lee CY, Chen MY, Tsai HC, Hsu HC and Tang CH: CCL5 increases lung cancer migration via PI3K, Akt and NF-kappaB pathways. Biochem Pharmacol 77: 794-803, 2009.

28. Grivennikov SI, Greten FR and Karin M: Immunity, inflammation, and cancer. Cell 140: 883-899, 2010.

29. Bond M, Fabunmi RP, Baker AH and Newby AC: Synergistic upregulation of metalloproteinase- 9 by growth factors and inflammatory cytokines: An absolute requirement for transcription factor NF-kappa B. FEBS Lett 435: 29-34, 1998.

30. Chen JJ, Lin YC, Yao PL, Yuan A, Chen HY, Shun CT, Tsai MF, Chen $\mathrm{CH}$ and Yang PC: Tumor-associated macrophages: The double-edged sword in cancer progression. J Clin Oncol 23: 953-964, 2005

This work is licensed under a Creative Commons Attribution-NonCommercial-NoDerivatives 4.0 International (CC BY-NC-ND 4.0) License. 